\title{
Avoid Costly Litigation: Ten Steps to Implementing LaWful HiRing Practices
}

Judith H. Holmes, JD

A malpractice claim or suit can have a devastating effect on a physician's practice and personal life. What is often overlooked is that an employment-related suit or EEOC charge also can extract a heavy toll, personally, professionally, and financially.

The number of employment-related suits and claims has risen dramatically in the last few years. According to recent enforcement and litigation statistics released by the U.S. Equal Employment Opportunity Commission (EEOC) (1), the total discrimination charges filed by individuals against their employers increased last year to 80,840 - the highest level since the mid-1990's.

According to the EEOC data, in 2001, employers paid $\$ 248$ million in connection with charges of discrimination filed with the EEOC by job applicants, employees, and former employees. Employers paid an additional \$47 million to the EEOC in connection with lawsuits filed against employers by the EEOC (2). This does not include the millions of dol-

The physician you hired and spent the last year training came in this morning and announced he's quitting medicine and moving to Tahiti to "find himself." Your nurse practitioner tearfully told you she's leaving to follow him. This happened just after you fired your bookkeeper when you discovered he has been keeping your money instead of your books. You do the only sensible thing: you panic. You can think of only one thing - you need help and you need it fast. You need competent, experienced, hardworking professionals. You

From Judith Holmes \& Associates LLC, Englewood, Colorado. Address Correspondence: Judith Holmes \& Associates LLC, 7887 E. Belleview Suite 1100 , Englewood, CO-80111.

E-mail: jdthhlms@aol.com or

judy@jholmeslaw.com

Funding: There was no external funding in preparation of this manuscript.

Conflict of interest: none lars employers were forced to pay in settlements, judgments, costs, and attorney's fees incurred in connection with employment-related lawsuits filed in state and federal courts during the same period of time.

Employment-related litigation is on the rise, and the healthcare industry is not immune. Physicians as employers can be a target for a wide range of employment-related claims and suits, such as breach of contract, invasion of privacy, sex, race, age, religious and age discrimination, and negligent hiring, just to name a few. The number of jury verdicts rendered against employers is increasing and the verdict awards are often staggering. In addition, defending these suits can be as expensive as defending a complicated malpractice suit. Even worse, employment discrimination suits and charges are generally not covered by malpractice, D \& O, or general liability insurance policies, leaving the physician to cope with the financial burden of judgments, settlements, attorney's fees

\section{and litigation costs.}

Most employment-related disputes that lead to costly litigation would never have arisen if the employer had implemented more effective employment practices. Hiring mistakes in particular cause many costly legal battles. This article identifies legal issues that precipitate litigation and suggests ten steps physicians can take to implement lawful hiring practices that will reduce the risk of costly employment suits while improving office efficiency, morale, and productivity.

NOTE: This article is intended as an overview of lawful hiring strategies, and is not a substitute for legal advice from experienced employment counsel. Applicable laws vary from state to state and appropriate procedures may depend on specific factual situations. This article is not, and should not be construed as, legal advice.

Keywords: Litigation, employment, hiring, discrimination, disabilities, training, office management. need them immediately. So you put an ad in Thursday's newspaper and instruct your receptionist to hire the first three applicants who walk through the door. Big mistake.

Implementing effective hiring procedures can be time-consuming and complicated, particularly when you are shorthanded and must take on much of the hiring burden yourself, or must delegate the task to your already-overworked office manager. But it is important to resist the temptation to skip the steps that can save you money and headaches in the future. From a practical standpoint, a thorough investigation of every prospective employee will reduce the chance of making the costly mistake of hiring an ineffective, unfit, or unproductive worker.

From a liability standpoint, implementing effective pre-hire screening procedures is of paramount importance. In addition to discrimination suits, in most states, employers may be sued for negligent hiring if the employer fails to exercise reasonable care in selecting employees who are fit for the employment position. If a coworker or third party is injured by an incompetent or violent employee, the employer may be held liable if it can be shown that an employer knew or, in the exercise of reasonable diligence, should have known that an employee posed an undue risk of danger to a coworker or third party. The failure to exercise care when hiring can be costly: in one recent case, a jury awarded the family of a murdered woman $\$ 46$ million against a home healthcare company based on the family's claim that her death was the result of the defendant's negligent hiring of an employee (3).

The following ten-step guideline will help protect you and your practice against 
the perils of being an employer.

\section{Step 1: Training Your Hiring Manager}

Probably the most important step in hiring an employee should happen before you advertise the opening. The person you put in charge of hiring must be adequately trained so that he or she understands the relevant discrimination laws and can manage the hiring process without stepping on the many landmines that can blow up in your face. It just takes one mistake to prompt a rejected applicant to file a discrimination charge with the EEOC.

Courts have upheld large verdicts against employers who have not recognized the importance of training managers to use lawful hiring practices. In a recent age discrimination case, the U.S. Court of Appeals for the Seventh Circuit (4) stated that it is an "extraordinary mistake" for a company to fail to train hiring managers regarding applicable discrimination laws. The court in that case upheld a jury award of $\$ 50,000$ in liquidated (punitive) damages - in addition to another $\$ 50,000$ in compensatory damages. In addition to the jury award of $\$ 100,000$, the company incurred substantial legal fees to defend the lawsuit and to respond to the EEOC charge. To add insult to injury, the company was also liable for the plaintiff/applicant's trial costs and attorney's fees. In short, the failure to train the hiring manager to comply with discrimination laws was not just an extraordinary mistake - it was an extraordinary expense.

What mistakes did the manager make during the hiring process that warranted such an angry response from the jury and the appellate court? First, in response to the "help wanted" ad, the applicant (who had 24 years of relevant experience) had submitted two separate applications, but did not receive an interview or even a response from the company. Second, after the applicant submitted his applications, the hiring manager hired seven salespeople to fill the open slots - and they were all younger than the 59-year-old plaintiff. Third, there was evidence at trial that one of the hiring managers often wrote notes listing all the applicants' ages, and used the notes in the hiring process. Fourth, a second manager admitted during testimony that he favored job candidates who were "bright, young, and aggressive."
The mistake that triggered the punitive damage award involved the hiring manager's admission that he did not know that age discrimination is illegal, despite the fact that the company's application form contained a statement that the company did not discriminate on the basis of age. The appellate court singled out this transgression with a stinging rebuke: "Printing this statement on the application but then making no effort to train hiring managers about the ADEA (5) shows that the (company) knew what the law required but was indifferent to whether its managers followed that law."

The moral of the story: If you delegate the interview process to a member of your staff, be certain he or she knows what to do and how to do it. Everyone on your staff who participates in the hiring process must be made aware of applicable discrimination laws and must be trained to avoid impermissible hiring practices that violate state and federal laws regarding age, disability, citizenship, race, national origin, marital status, pregnan$\mathrm{cy}$, and religion.

\section{Step 2: Advertising the Job Opening}

Believe it or not, potential liability for unlawful hiring practices begins at the time you advertise the job opening. If you place an advertisement online or in the "Help Wanted" section of the newspaper, the words you use may trigger age, sex, race, or disability claims by those potential applicants who do not meet the qualifications you describe. For example:

- Using terms such as "young, energetic" or "recent college graduate," placing age or sex limitations in the ad ("female, age 22-35"), or placing the ad only in a section segregated by male and female workers may trigger age or sex discrimination claims.

- Using the term "energetic, attractive appearance a plus" may trigger a disability or race discrimination claim, and requiring a "pleasant telephone manner without accent" may trigger a national origin discrimination claim.

- At this stage of the hiring process, it is important not to request that applicants submit photographs with their resumes or applications, since this practice may trigger discrimination claims based on age, disability, sex, race, or national origin.

- At this stage, as well as throughout the hiring process, it is important to avoid the temptation of overselling the job benefits. Using terms such as "stable, long term employment" or "long term career opportunities" may come back to haunt you later in the form of a breach of implied contract claim in the event a subsequent termination or layoff is required (6).

\section{Step 3: Drafting Your Job Description}

In most cases, is advisable to have a written job description. A clearly defined job description may be useful in the hiring process, by giving applicants a very clear indication of what will be expected of them if they are hired. Job descriptions are also helpful in connection with disciplinary situations and in disputes with employees as to what is expected of them ("You never told me I'd have to do THAT!").

When drafting the job description, you may include the hours and the days of the week the employee will be expected to work, and whether there are overtime requirements. You should describe the job duties in reasonable detail, but you should make certain the wording does not unreasonably restrict you from adding or modifying the duties as necessary. The most important aspect of a written job description is the identification of the "essential functions of the job," or the core set of duties the employee must be able and willing to perform, and are required of the employee in order to fulfill the job functions.

Step 4: Revising Your Application Form

You may be tempted to accept a curriculum vita or resume in lieu of requiring the applicant to fill out a formal application form. There are several obvious reasons to resist this temptation. Resumes are often little more than creative writing samples. Clearly, an applicant can misrepresent or omit important background information, whether he submits a resume or fills out an application form. However, it is easier for an applicant to omit negative information in a resume. When you review a slick, wellwritten resume, you may not realize that there is an eight-month gap in the applicant's employment history. Did the applicant spend that time in a training program or in a prison or mental health facility? A resume supplied by the applicant may be full of descriptions of dazzling accomplishments, but fail to disclose that 
his professional license was suspended for three years. Using a standard application form that requires the applicant to answer specific questions regarding work history, exact dates of employment, and licensing information will make it more difficult for an applicant to omit information employers should know.

The application form you use is very important. It can be an effective, inexpensive tool to eliminate poor job candidates and help you zero in on the good prospects. However, an application form that makes improper, irrelevant or unlawful requests may lead to very costly hiring mistakes, and, worse yet, could lead to EEOC charges being filed against you. Whatever type of form you use, it is important to make certain that the application does not request any information that would reveal the applicant's age, race, religion, national origin or other category protected by applicable laws. With that caveat in mind, consider the following checklist:

- The application form should contain a statement that you are an equal opportunity employer and that you maintain a policy of treating all of your applicants and employees without regard to race, gender, national origin, religion, national origin, age, citizenship, or any other characteristic protected by law. The statement should make clear that this policy applies to all employment decisions, including but not limited to recruiting, hiring, compensation, promotions, termination, and all other terms and conditions of employment. (NOTE: Be sure to adopt and consistently apply these policies in your office.)

- The application should contain a request for the applicant's social security number, and a list of every address the applicant has lived in the past 10 years. This is important for use in the background check, discussed below.

- A complete description of the applicant's educational background, vocational training, and degrees earned. Although it is appropriate to ask the applicant to include the dates of attendance at colleges and vocational schools, it is not advisable to ask the applicant the dates he or she attended high school, or the date of graduation from high school, since this information can be used to calculate the age of the applicant.

- The application should require the ap- plicant to disclose whether he or she has been convicted of a violation of any law or ordinance since age 18 . The request should exclude offenses committed when the applicant was a juvenile. You should not limit your inquiry to felonies, since you may miss learning of a serious offense involving dishonesty, violence, or crimes against children.

- Unless limited by state law, your inquiry should not be limited to only recent convictions. A conviction may have occurred 10 years ago, but if it was for a crime of violence or involved a sexual offense against a child, you should know about it in order to take it into consideration, particularly if you are hiring for a position in which the employee will have contact with patients or children.

- It is advisable to limit the inquiry to convictions, and not merely arrests (7). It is also important to have a statement on the application form that a record of conviction will not necessarily preclude an applicant from being hired. In fact, all employment decisions should be based on job-related factors. For example if an individual is applying for a receptionist position he or she should not be rejected solely on the basis of a DUI conviction. However, if you are hiring an employee whose job duties will include driving during business hours to make deliveries or to transport patients, that same DUI conviction is a valid and important consideration, particularly if the offense is recent.

- It is very important to get a complete, comprehensive employment history from the applicant. The application form should request that the applicant submit a detailed job history beginning with the most recent job. For each of the applicant's previous jobs, you should request the name of the employer, the name of at least one former supervisor, the job title, the starting and ending salary, the applicant's reason for leaving, and whether or not you have the applicant's permission to contact the former employer for information and verification. It is important to get specific dates the applicant worked for each employer, so that you can spot any gaps in employment and follow up by finding out why the applicant was unemployed, and what he was doing while he was unemployed.

- You may also request information about the applicant's military background, including branch of service, length of service, rank attained, and type of specialization. There are two caveats: requesting information regarding the type of military discharge may reveal a medical disability, and requesting dates of service may reveal the approximate age of the applicant.

- The information you may elicit relating to disabilities should be limited at the application stage. You should not include inquiries such as "Do you need an accommodation to perform this job?" or "Can you do these functions with___or without___ reasonable accommodation? (Check One)" (8).

- It is helpful to have a written job description available to the applicant that details the job duties and requirements, and specifically spells out the essential functions of the job. The application form may then refer to the attached job description, and ask the applicant: "Can you, with or without reasonable accommodation, perform the essential functions of the position for which you are applying?"

- At the end of the application, the applicant should be required to sign a certification that all of the information contained on the application form is true and complete and that the applicant understands that any false statement made or any information omitted will lead to the rejection of the application. The certification should also state that the applicant acknowledges that if he or she is hired, any falsification or omission that is later discovered may result in discipline, up to and including termination at the time the false statements or omissions are discovered.

- If you have developed and adopted a policy that all employment related claims must be submitted to mandatory arbitration, that policy should be clearly stated in the application, along with an acknowledgement that the applicant agrees to submit all claims and disputes relating to the hiring process and employment relationship to the arbitration process (9).

- The application should contain an acknowledgement that any offer of employment extended will be contingent upon satisfactory completion of a medical examination, including a drug test, and that any offer of employment is being made contingent upon submission 
of proof of credentials and licenses.

- The applicant should acknowledge that he understands the application is valid only for the position that is currently open, and that there is no obligation to consider the applicant for any future openings.

- The application should include a statement advising the applicant that his signature on the application authorizes you or your group, as the potential employer, to conduct a background check, and to obtain information from former employers, educational institutions, and other sources that may have relevant information.

- Unless you intend to enter into a specific contractual agreement to the contrary, you should make it clear, not only on the application form but throughout the entire hiring process, that there will be an "employment at will" relationship, and that the employee may be terminated at any time for any reason, with or without cause or notice.

- The application form, as well as the employee handbook should clearly state that no modification of this at-will relationship is valid unless the change is in writing, signed by you (or the group's authorized agent). Requiring all applicants to acknowledge the at-will employment relationship in writing will reduce the chance that an employee will be successful in making a claim that he was promised job security, such as a three-year "no-cut" deal, or that he was promised that he would not be subject to layoff unless he was given a large severance package.

\section{Step 5: Interviewing The Candidates}

Once you have completed a preliminary screening of the applicants and have scheduled the finalists for personal interviews, take time to determine what questions you need to ask to maximize your chances of weeding out unqualified candidates. In general, your questions should be job-related and should carefully avoid subjects that may trigger a discrimination claim. Keep in mind that after the interview process is completed and a conditional job offer of employment is extended, you will be less restricted. At that point, you may elicit additional information regarding medical history, past illnesses, workers' compensation claims, and other relevant information.

The following are a few tips on in- terview questioning. This is just a sample of the many issues that relate to lawful questioning. Proposed interview questions should be reviewed with your employment counsel prior to conducting the interview.

- It is advisable to have the appropriate interview questions in written form, and to caution the interviewer to "stick to the script." This will reduce the chance that the interviewer will make offhand comments that may trigger a claim of discrimination by an unsuccessful applicant. ("We don't hire people who have filed worker's comp claims (10)," or "apply again after you have your baby" (11).

- As a general rule, questions asked of and information elicited from an applicant during the interview stage and the hiring process should be job-related and motivated by legitimate business concerns (12).

- Drug Use: Phrase the questions carefully, particularly when there is a danger you may inadvertently elicit information regarding a disability, in violation of the ADA. For example, you may ask an applicant about current use of illegal drugs, because the ADA does not offer protection at any stage of the hiring process for an applicant who uses illegal drugs. However, you should not ask an applicant about current use of legal drugs, such as "What medications are you currently taking?" or "Have you ever taken AZT?" This topic is "off limits" because you may elicit information regarding a disability.

- Religion: You should not ask an applicant about his religious affiliation, or what religious holidays he or she observes. However, you may discuss overtime and shift issues, what days and hours the applicant will be expected to work, and ask the applicant if he or she is able to meet those requirements.

- Race/National Origin: You should not comment on the applicant's "interesting last name" or question an applicant about his or her nationality. You should not ask where the applicant was born, or whether he or she is a naturalized citizen. You may ask whether the applicant is authorized to work in the United States. You may advise the applicant that if hired, he or she will be required to produce proof that he or she is authorized to be employed in the
U.S.

- Sex/Marital Status/Pregnancy: You should not ask an applicant about marital status, or the ages of his or her children. You should not ask "Do you plan on having more children?" or "Do you have reliable day care?" or "Is your husband willing to help with child care issues that arise?" Stick to the real issue by asking whether the applicant anticipates having any obligation or commitment that would prevent him or her from working the regular and overtime work schedule you describe in the interview or in the written job description.

\section{Step 6: Assessing Disabilities}

Throughout the hiring process, the potential employer must avoid improper inquiries regarding disabilities, since improper questioning may result in costly suits. In general, employers may not require that an applicant reveal a physical or mental condition, and then use that information to exclude the applicants with disabilities before their ability to perform the job is evaluated. This can lead to EEOC intervention and disability discrimination lawsuits (13). Wal-Mart recently learned that lesson the hard way when it agreed to pay $\$ 7$ million to settle a lawsuit filed by the EEOC for using a pre employment questionnaire called a "Matrix of Essential Job Functions." The EEOC charged that the test violated the ADA by disclosing an applicant's disabilities before a conditional offer of employment was made.

The EEOC has published guidelines to be used when asking pre employment, disability related questions. The guidelines are applicable to employers who are subject to the Americans with Disabilities Act and who are not subject to affirmative action provisions of other federal acts. Although your practice group may not be subject to the ADA (14), applicable state laws may impose similar requirements. Therefore, it is advisable to use the EEOC guidelines as a framework for dealing with the issue of disability in the hiring process.

Although a detailed discussion of the ADA is beyond the scope of this article, when formulating your hiring policies and procedures, consider the following general points:

- The ADA and similar state and federal disability discrimination laws apply to individuals who have obvious dis- 
abilities, such as those who are deaf, blind or in wheelchairs. The ADA may, depending on the circumstances, also covers people who have physical conditions such as diabetes, HIV, and epilepsy. Individuals with a mental impairment such as major depression or bipolar disorder may also be covered. The ADA also protects a person who is "regarded as having a disability" such as an individual who has cancer that is in remission (15).

- The ADA does not require an employer to hire a disabled applicant instead of a non disabled applicant. However, an employer may not refuse to hire a disabled applicant solely because he or she needs an accommodation to perform the job duties (such as a special phone adapter for the hearing impaired.)

- You may ask about the applicant's skills, education, and training, and whether the applicant can, with or without reasonable accommodation, perform the essential functions of the job. However, prior to extending a conditional job offer, you should not ask questions regarding the applicant's physical or mental impairment, how the applicant became impaired, or what type of medications the applicant is taking (16).

- You may ask how much time off the applicant took in a previous job, the reason the applicant left a prior job, and what disciplinary action the applicant received at a previous job. You should not ask whether an applicant has filed worker's compensation claims, and you should not ask whether absences from a previous job were due to illness, since that may reveal information relating to a disability (17).

- There are times during the application process where it becomes obvious to a potential employer that an applicant has a disability that will require a reasonable accommodation. In those cases you may make appropriate inquiries. For example, if an applicant comes to the job interview in a wheelchair, or if it is obvious that the applicant has a significant vision or hearing impairment, you do not need to ignore the condition. You may ask the applicant if he or she will need an accommodation, such as a modified computer or telephone equipment, to perform the job duties. You may also ask the applicant to demonstrate or describe how he or she would perform the job duties (18).
- When considering whether a prospective employee is an appropriate candidate for the job, keep in mind that the ADA does not require an employer to hire an individual that poses a direct threat to the health or safely of coworkers or to himself (19).

\section{STEP 7: Conducting a Background} check

The importance of conducting an effective background check cannot be over emphasized. To save time and expense, you may be tempted to skip the investigation step and hire an applicant who looks good on paper, and who interviews well. However, if you fail to conduct an adequate investigation, you may not discover until it's too late that the applicant's job history includes terminations for poor attendance, dishonesty, or workplace violence, or that the applicant has fabricated important aspects of his training, criminal background, or professional credentials. In fact, an employment screening company (20) reported that when it conducted background checks on a group of applicants and compared the results with the applications they submitted, there were notable discrepancies. Of the group studied, $8 \%$ of the applicants claimed to have attended an educational institution that had no record of the applicant's existence, and $11 \%$ of the applicants had listed previous employers that either did not exist, or that had no record of the applicant having been employed. Another 11\% of the applicants had criminal records that were discovered in the background check, but not divulged in the application.

Inadequate background checks may subject physicians and group practices to liability for harm caused by the employee. Conversely, if an employer is sued for negligent hiring, evidence that the employer had conducted an appropriate background check will be a powerful defense to that claim, even if the background investigation failed to uncover the facts that would render an individual unfit for employment (21). It is therefore important that your background check be thorough, yet reasonable under the circumstances. When you conduct a background check:

- First, review the completed application to make sure the applicant has provided all of the information requested. It is astounding how often employers never actually review and analyze the information contained in the applications that are submitted. Spotting evasive answers, obvious omissions, or gaps in reported employment history can eliminate undesirable job candidates at an early stage, even before you waste time conducting a background check on those individuals.

- Obtain the applicant's written authorization to conduct the background investigation. The authorization should specifically include the applicant's consent to contact former employers and references, and to obtain information regarding driving and professional licenses, educational records, financial records, criminal records, and any other public records you intend to use as part of your background investigation.

- Tailor the extent and content of the background investigation to the actual job duties. If you are hiring a nurse who will be assisting you during office procedures and who will have frequent contact with your patients and access to sensitive information, or if the job requires administering drugs, the background check on professional and educational credentials should be more in-depth than you would need to conduct when hiring a receptionist or transcriptionist. Similarly, if the job requires the employee to have access to your business bank account or to other valuable property, your background check should include a more in-depth investigation of the applicant's financial background. In that case, an applicant's recent bankruptcy or a conviction involving dishonesty may take on special significance. However, it is important to keep in mind that denying employment based solely on an applicant's bankruptcy is considered unlawful discrimination and is prohibited by federal law (22).

- You do not need to conduct the same investigation on every applicant for every job. However, you should conduct the same investigation on all applicants who apply for the same job. If you single out certain applicants for more scrutiny than others, you risk liability for discrimination.

- Despite the fact that many states have laws extending qualified immunity to former employers who divulge information to prospective employers, there is a general reluctance on the part of previous employers to answer questions about a former employee or to cooperate in any other way with a background 
check. You may be more successful in getting information from a former employer if you present a signed authorization from the applicant specifically authorizing former employers to respond to your requests for employment information.

You may decide to retain the services of an outside agency to conduct a background check on potential employees. Using an outside agency can be efficient and cost effective, particularly for individual physicians or small group practices. Using an experienced outside agency may also provide limited immunity to employers against suits based on claims of defamation, invasion of privacy, and negligence (23).

- If you decide to delegate the investigation to an outside agency, be sure to choose the agency carefully, since you may incur liability in the event the agency fails to follow lawful procedures. It is advisable to enter into a written contract with the agency, that includes an indemnification provision and an acknowledgment that the agency carries liability insurance and agrees to comply with all applicable laws relating to conducting backgrounds checks.

- Believe it or not, if you retain an outside agency to conduct a background check on a prospective (or current) employee, the report generated is considered a "consumer investigation report." As such, the investigation process and the report issued are subject to the rules and regulations of the Fair Credit Reporting Act (FCRA), triggering several important requirements and obligations on the part of the employer relating to disclosure, consent, certification, notification, and permissible uses of the report.

- A broad range of communications and investigative reports relating to applicants and employees, including criminal and motor vehicle records, are subject to the provisions of the FCRA if the information is supplied to an employer by a consumer reporting agency to an employer. You should assume that any pre-employment report that is prepared by an outside agency is subject to the many requirements of the FCRA (24).

- A detailed discussion of the requirements imposed by the FCRA is beyond the scope of this article. However, em- ployers should be aware of the issue, and consult with legal counsel to make sure your investigation procedures comply with the law.

\section{Step 8: Pre-Employment Testing}

There are several types of pre-employment tests that may be useful in screening applicants for a particular job. Lawful tests range from drug and medical tests, to honesty, aptitude, personality, and skill tests. You should determine what tests, if any, are appropriate for the particular job for which the applicant is applying, and limit the types of tests to those you can justify in terms of legitimate business necessity, reasonableness, and job relatedness. Your need for test results must always be balanced against privacy concerns. Always keep in mind applicable drug testing laws, which vary from state to state. Also keep in mind state and federal antidiscrimination laws, such as the ADA and Title VII, since improper testing can trigger liability under those laws and acts.

In general, you should not require an applicant to submit to medical tests before extending a conditional job offer. There is one notable exception. Under the ADA and most state laws, you may test for current use of illegal drugs at any time prior to or during employment. You are not required to extend a job offer to an applicant or to retain an employee who is currently engaging in the use of illegal drugs. When choosing and administering pre employment tests:

- You must give the same medical or physical exam to all individuals who are being offered the same type of job. For example, if you are hiring two nurses who will be required to lift patients, you may extend employment offers that are conditioned on the results of a physical strength test. However, you must require that every individual applying for that job position take the same test. You may not single out only the applicant who walks with a limp or an applicant who is older than the others.

- You may withdraw an offer from an applicant with a disability only if it becomes clear that the applicant cannot perform the essential functions of the job or if the individual would pose a direct threat to himself or others. For example, if you extend an offer to a nurse whose job function will include assist- ing you with procedures, you may withdraw the offer if you learn that he or she has frequent or unpredictable seizures.

- Regardless of the pre employment tests you use, keep in mind that you may not reject a job applicant merely because of a disability. You may be required to provide a "reasonable accommodation" to enable an individual with a disability to perform the job functions. The type of accommodation and the reasonableness of the necessary modifications are determined on a case-by-case basis, and will depend on the individual, the disability, the employer's needs, the cost of the accommodation, and the essential functions of the job. You should consult with experienced employment counsel for advice on handling disability issues that arise during the hiring process.

Step 9: Documenting the Hiring Process - Carefully, Appropriately, Thoroughly, and Defensively

During the entire hiring process, you should keep in mind three important words: DOCUMENT, DOCUMENT, and DOCUMENT. Think defensively and assume every hiring decision will be scrutinized by an EEOC investigator or by an attorney hired by an unsuccessful applicant. You may be called upon to justify your decision to hire one candidate over another. It is important to document your legitimate, non-discriminatory, business-related reasons for making your decisions. Carefully drafted documentation will help you defend your hiring decision when confronted with allegations of unlawful discrimination, invasion of privacy, breach of contract or negligent hiring. Document at every stage of the hiring process:

- The Job Advertisement: Document this phase of the hiring process by retaining a copy of the advertisement as well as a list of the publications where it appeared and the dates you ran the ad. Similarly, if you advertised on the internet, keep a printout of the wording and the websites on which the ad appeared.

- The Applications: Be careful what comments and notations you make about applicants on their resumes and applications. Resist the temptation to record anything about the applicant that is not directly job-related, and be sure that the notations cannot be construed as a derogatory comment about 
the applicant's sex, race, religion, national origin, pregnancy, military service, age, or disability. As discussed earlier in this article, inappropriate notations made on the applicant's resume or application ("Might not be around very long" (25) or "articulate but unattractive") can be devastating evidence against an employer in an age or sex discrimination case.

- The Authorizations and Certifications: Save copies of the applicants' signatures on the authorizations to contact prior employers and to conduct background checks described earlier in this article, so that you can defend against an invasion of privacy or breach of contract claim filed by those applicants with short memories of what agreements they made. Include as part of the employees' permanent file the signed statement in the application, certifying that the information he or she supplied was true and accurate. If you later discover material misrepresentations in the information, you will be on firmer ground to terminate the dishonest employee.

- The Interview: It is advantageous to save a copy of the interview script you used, listing the questions asked of the applicant. Make sure the notations you make are appropriate and job-related. This record will help you defend against later claims by an unsuccessful applicant that the questioning violated the ADA, Title VII or other applicable law.

- The Background Check: Maintain records of the information you received in connection with the background investigation you conduct. If you use an outside agency or investigator, be sure to your documentation and authorizations comply with the requirements of the FCRA.

- Verifying Background Information: Check all references, and document what was said about the applicants. You may get frustrated when you attempt to verify aspects of the applicant's employment history, since many employers are reluctant to divulge any information about former employees. Even if you get no cooperation from former employers, you have not wasted your time. Record the efforts you made to obtain the information, such as the name of the individuals you talked to, what information you requested, and document their refusal to cooperate. In the event that you hire the applicant and he is later responsible for an act of workplace violence or harassment of a coworker, you may be the subject of a negligent hiring suit. In that event, you will need to demonstrate that you exercised reasonable care when you hired the individual. You will be able to demonstrate with your documentation that you interviewed the individual's references and former employers and that they did not warn you of any violent propensities or previous incidents of harassment.

- Former Employers' Comments: Ask all of the applicant's former employers if the applicant is "subject to rehire." If they response in the negative, request an explanation. It is advisable to then give the applicant an opportunity to respond to the negative information.

- Pre-Employment Testing: Maintain test results and document the reasons you chose specific types of tests. You may be called upon to verify that your choice of tests, testing procedures, and your hiring decisions did not unlawfully discriminate against a protected group, such as the disabled.

\section{Step 10: Getting It In Writing}

Once you have found the perfect employee, it is advisable to prepare a written offer letter, acknowledging the specific terms and conditions of employment. Get the prospective employee's signature on the letter before he or she begins work. The offer letter should memorialize allimportant aspects of the future employment relationship, such as:

- Job title, starting salary, insurance and other benefits, as well as any agreements relating to future compensation, profit sharing, bonuses, raises or other financial arrangements.

- Unless you intend to enter into a contractual arrangement, the offer letter should include an acknowledgement that there will be an employment at will relationship.

- Include your policy statement prohibiting discrimination and harassment. Also include your mandatory reporting procedures, together with a statement that the employee agrees to abide by the policies.

- An acknowledgement of your confidentiality policies.

- If you intend to enter into a covenant not to compete, you should reference it in the offer letter. You should review the non-compete terms with experienced counsel, since a poorly worded or overly broad agreement may be unenforceable.

\section{Author Affiliation:}

Judith H. Holmes, JD

Judith Holmes \& Associates, LLC

7887 E. Belleview Suite 1100

Englewood CO 80111

Phone: (303) 228-2267

E-mail: jdthhlms@aol.com or judy@jholmeslaw.com

\section{REFERENCES}

1. U.S. Equal Employment Opportunity Commission Enforcement Data, Fiscal 2001, released February 22, 2002. The EEOC enforces federal discrimination laws, including Title VII of the Civil Rights Act of 1964 which prohibits employment discrimination based on race, age, national origin, religion, and gender. The EEOC also enforces the Age Discrimination in Employment Act (ADEA), the Americans with Disabilities Act of 1990 (ADA), and the Equal Pay Act (EPA). With the exception of the EPA, individuals must file a Charge of Discrimination with the EEOC and receive a "Right to Sue" letter from the EEOC as a condition precedent to filing a discrimination lawsuit in state or federal court. The EEOC has the authority to investigate the employee's claim. Following the investigation, the EEOC may attempt to obtain a settlement with the employer on behalf of the charging party. The EEOC also has the authority to file suit as the named plaintiff on behalf of the employee(s) who filed the charge against the employer.

2. Fair Employment Practices, Bureau of National Affairs, Inc., Vol.38, No.938 (January 3, 2002).

3. Gurkin v. The Nurse Connection, Inc. No. OCN-L-4017-95, filed in Superior Court, Coean Co. N....

4. Mathis v. Phillips Chevrolet Inc., 269 F $3 \mathrm{~d}$ 771 (7th Cir. 2001). The Seventh Circuit covers Illinois, Indiana, and Wisconsin.

5. Age Discrimination in Employment Act, 29 U.S.C. §621-634.

6. Lazar v. Superior Court, 909 P. 2 d 981 (Cal. 1996).

7. The EEOC and some state courts have held that employment decisions that rely on arrest records can have a disparate impact on minorities, based on the premise that minorities are arrested at a greater rate than Caucasians.

8. ADA Enforcement Guidance: Pre employment Disability-Related questions and Medical Examinations Under the Americans with Disabilities Act of 1990 (EEOC 
Oct. 10, 1995) (hereinafter "EEOC ADA Guidelines").

9. The adoption of an arbitration procedure should be discussed with your employment counsel. If mandatory arbitration is adopted, many employers used the procedures set out in the Federal Arbitration Act, 9 U.S.C. Section 1-16 or similar state procedure.

10. In one recent case filed by the EEOC, a similar comment that was allegedly made during an interview cost the employer almost $\$ 30,000$, plus attorney's fees incurred to defend the action. (EEOC v. Arrow Forklift Parts, Inc., W.D. Mo., NO. 40-00-00456-CVW-6-HFS)

11. This comment may be considered a violation of the Pregnancy Discrimination Act,
42 U.S.C. $\S 2000 e(k)$ which prohibits discrimination on the basis of pregnancy.

12. 29 C.F.R 1630.10.

13. EEOC ADA Guidelines

14. The ADA applies to employers who employ 15 or more employees. In Clackamas Gastroenterology Association, P.C. v. Wells, 538 U.S. 440 (2003), the U.S. Supreme Court recently held that a physician who is a shareholder of a professional corporation, such as a medical clinic, may, under some circumstances, count as an "employee."

15. ADA, 42 U.S.C. $\S$ 12101(1990); Primer for Small Business, U. S. Equal Employment Opportunity Commission.
16. id.

17. id.

18. EEOC ADA Guidelines, supra.

19. Chevron U.S.A. Inc v. Echazabal, 536 U.S. 73 (2002)

20. From statistics compiled in 200 by HireRight, Inc.

21. Cotran v. Rollins Hudig Hall Int'l, 17 Cal. $4^{\text {th }}$ 93 (1998)

22. 11 U.S.C. $\S 525$

23. The National Employer, vol. II, Littler Mendelson, p. 652 (2002/2003 ed.)

24. id at p.655.

25. Danville v. Regional Lab Corp. 292 F. 3d 1246 (10 ${ }^{\text {th }}$ Cir. 2002).

\section{Important Addendum}

As this article goes to press, President Bush has just signed legislation modifying the provisions of the FCRA, loosening the requirements relating to third party investigations of employees and applicants. The FCRA amendments just signed into law in December 2003 exclude many of the previous restrictions imposed on employers relying on third party investigations of employees and applicants. It is important to consult with experienced employment counsel to review these changes before conducting any type of employment investigation. 